\title{
In Their Own Voices: Experiences of Dalit Students in Higher Education Institutions
}

\author{
Rakesh Kumar Maurya \\ University of Wyoming \\ U. S. A.
}

ABSTRACT: This qualitative study explores the experiences of Dalit students in one of the state universities of Uttar Pradesh in India. An Interpretative Phenomenological Analysis (IPA) was conducted to understand the experiences of Dalit students at higher education institutions, including castebased prejudice and discrimination on campus. A total of seven themes emerged indicating caste-based prejudice and discrimination against Dalit students in both explicit and subtle ways at various levels of the university. Caste-based discrimination, humiliation, and exclusion were experienced by Dalit students at the level of fellow students, faculty, and administration.

KEYWORDS: Dalit, caste, higher education, discrimination, India.

Review of Literature

Methods

Results

Discussion

Conclusion

References

Appendix A: Participant Details

Appendix B: Semi-structured Interview Questions

Author Contact

Rohit Vemula, a Dalit research scholar at the Hyderabad Central University, hanged himself in his friend's hostel room on January 17, 2016. In his suicide note he wrote, "My birth is my fatal accident.... I always was rushing. Desperate to start a life...I am not sad. I am just empty. Unconcerned about myself. That's pathetic. And that's why I am doing this" (Biswas, 2016, para.1).

This unsettling suicide note has brought forth the gruesome reality of castebased discrimination, exclusion, and humiliation of Dalit students in the premier educational institutions of India. However, this is not the first time a Dalit student committed suicide. Bal Mukund, another Dalit student from Uttar Pradesh, committed suicide in his hostel room at the All India Institute of Medical Sciences (AlIMS) in 2010 (Deshpande \& Zacharias, 2013). He decided to end his life after constantly being taunted by faculty and fellow students as a "quota guy." "How could Chamars become doctors? You are here only because of quota, you would not be able to go ahead from here" were the usual taunts that haunted him in classrooms, hostel, and the canteen (Karthikeyan, 2011, para. 4). Chamar is one 
of the untouchable communities under the Indian caste system. The quota, or reservation system, is similar to the affirmative action policies in the United States. However, unlike the United States where fixing quota or awarding extra preferential points for targeted social groups is not practiced (Feinberg, 2005), in India a certain percentage of seats in government-run institutions are reserved for people belonging to schedule castes (SCs), schedule tribes (STs), and other backward classes (OBCs) as part of affirmative action policy. Hence, caste is adopted as a basis for implementing affirmative action policies, as caste has been the basis for discrimination, exclusion, and humiliation for thousands of years in India (Maheshwari, 1997). The SCs and STs refer to castes that have officially been designated as historically disadvantaged social groups in India (Tripathy et al., 2016). The OBCs is a collective term used for castes that are educationally and socially disadvantaged (Tripathy et al., 2016).

The quota or reservation system was devised to make education accessible to the underprivileged castes by setting aside a certain percentage of seats for enrollment of students from Dalit and other marginalized sections of society. Out of 25 students who committed suicide between 2007 and 2013, 23 were Dalits (Thorat, 2016). While systematic data do not exist for Dalit students' suicides in higher education institutions, according to the National Crime Records Bureau (NCRB), every 11 minutes a crime was reported against a Dalit ranging from rape, beatings, and land-related violence in 2014 , which is more than $29 \%$ as reported in 2012 (Couderé, 2016).

Allegations of discrimination, humiliation, and exclusion have been vehemently denied by the higher education institutions arguing that these suicides took place because those students were unable to adjust to the rigorous educational environment of the institution (Singh, 2013). Even the government has treated these suicides as isolated incidents and, despite the Thorat Committee's findings of discrimination against Dalits, took no further step to stop such practices in educational institutions (Singh, 2016). The Thorat Committee was set up in 2007 following grave and widespread allegations of differential treatment and discrimination against students from Dalit and other marginalized sections of society in higher education institutions.

The discussion in media, society, and intellectual forums about discrimination against Dalits in higher education seems to be divided into two types of narratives. First, despite constitutional safeguards provided to Dalits, they are subjected to caste-based discrimination, humiliation, and exclusion, albeit in an implicit way (Thorat, Tagade, \& Naik, 2016). Implicit discrimination includes apathy of institutions in taking action against those responsible when such complaints are reported by Dalit students; passing derogatory comments such as "Sarkari Damads" ( government sons-in law), "Sarkari Brahmins" (government Brahmins), or "quota student"; and making Dalit students feel that they do not deserve to be there. Other forms of discrimination include avoidance, contempt, noncooperation, discouragement, and differential treatment by faculty towards these students (Thorat et al., 2016; Thorat, Shyamprasad, \& Srivastava, 2007). The second narrative suggests that most Dalit students are not bright enough; they are 
enrolled in higher education with the help of the quota system and, therefore, are unable to withstand the rigorous academic environment of higher education. Their inability to cope with the rigorous academic environment causes depression among Dalit students, and they, in some cases, take the extreme step of suicide (Kumar, 2012; Rehman, 2017). The existence of these two diametrically opposite narratives may be a factor as to why the government did not implement the Thorat Committee's recommendations. The Thorat Committee found caste-based discrimination against Dalit and other marginalized groups and made several recommendations to address the issue. However, the Committee's findings and recommendations were rejected by AIIMS, calling them biased and unsubstantiated (Dhar, 2016).

Because of these two diametrically opposite narratives, there is a need to explore experiences of Dalit students at higher education institutions. The current qualitative study seeks to explore experiences of Dalit students at one of the public state universities in the state of Utter Pradesh that leads the country in the number of registered crimes against Dalits in India (Pathak \& Sampath, 2016).

\section{Review of Literature}

As part of UK-India Education and Research Initiative (UKIERI), Thornton, et al. (2010) collected data at five higher education institutions in India and the United Kingdom to explore experiences of students and staff regarding equality and discrimination. These researchers observed that "separation of groups on the higher education campus is pervasive and ubiquitous. While some of such separation may be for supportive reasons, at other times it is due to overt discrimination on the grounds of race, region, nationality, caste, class, religion, or gender" (p. 1). A clear concern was expressed by some reserved-category students regarding inequitable treatment by upper caste (UC) students regardless of their academic ability. Also, dining areas and living accommodations on campus were places where segregation was observed. Dalit students dine together and students from unreserved categories hardly dine with Dalit students on a regular basis. Another barrier identified by this study is the lack of command over English, which prohibits Dalit and other marginalized students from participating in classroom discussions. Another study on experiences of Dalit students in a prestigious Indian university concluded, "This University is yet another arena in which the practice of caste division continues to exist. The university environment reinforces and maintains a divide between Dalit and non-Dalit. Dalit students do, indeed, experience overt and covert discrimination based on caste at this premier university" (Ovichegan, 2013, p.1).

While the above studies were limited to a few educational institutions, Singh (2013) interviewed and followed the life histories of eleven Dalit students who have survived the heavy odds and successfully made it through higher education from the best institutions of the country. Four main areas of discriminatory behavior were identified: experiences of prejudice and discrimination before entering higher 
education, teachers' attitudes and actions, animosity and exclusion from fellow students, and apathy and sometimes opposition from administrative officials. Singh (2013) further argued that, apart from the economic constraints and related contempt that the poor face, Dalits are also required to overcome castestigmatized identity before entering higher education. However, he argues, it is the absence of a supportive community that amplifies challenges for Dalit students and leaves them to face the challenges on their own. And after facing all these challenges, if they survive to enter higher education, further challenges await them in the form of apathy and sometimes hostile attitudes of teachers, fellow UC students, and administrative officials (Singh, 2013).

Sukumar (2013), a Dalit scholar who teaches in the department of political science at the University of Delhi, wrote an autoethnography in which he shared his own experiences of being a Dalit student at the Hyderabad Central University. He shared how the first generation of learners from Dalit communities had to come to terms with an alien curriculum along with entrenched pedagogical prejudices. As the first generation of Dalit learners lacks family guidance to deal with issues related to admission processes and information gathering regarding fee structure, courses, hostel facilities, and other related matters, they are dependent on university administrators who mostly have a lackadaisical attitude towards them. Also, as Dalit students do not possess the means to dress well and cannot speak in a polished tongue, they are neglected on social occasions such as birthday parties and cultural festivals. Additionally, because of their educationally deprived social background, Dalit students lack English language skills, which results in further alienation of Dalit students.

The above-mentioned studies are focused on experiences of Dalit and other marginalized students in premier and urban-based universities. There is no study on experiences of Dalit students in higher education institutions based in small towns or rural areas. The present qualitative study explores experiences of Dalit students in one of the state universities located in a small town of Uttar Pradesh in India.

For the present study, Social Identity Theory (SIT) from social psychology is used as a theoretical framework to inform the emerging themes and theoretical ideas from the data. SIT was originally formulated by Henry Tajfel and John Turner in the 1970s to introduce the concept of social identity to explain psychological underpinnings of intergroup behaviors (Abrams \& Hogg, 2016). According to this theory, three psychological processes are involved in how individuals create and define their place in society: social categorization, social identification, and social comparison (Turner \& Reynolds, 2001). While social categorization is a natural cognitive process through which humans categorize people in various social groups to reduce the complexity of navigating through the social world, social identification explains how individuals adopt the identity of the group they think they belong to and act in ways they think their group acts (Plous, 2003). Social comparison, the third psychological process, refers to the tendency of groups to distinguish themselves from other groups in an effort to make their in-group look 
better (Turner \& Reynolds, 2001). SIT offers a cogent psychological explanation of intergroup discrimination, exclusion, prejudice, and conflict.

The following research questions are addressed in this exploratory study.

- What are the experiences of Dalit students with faculty, fellow students, and administration at the University of Himalaya (pseudonym)?

- What are the perceptions of Dalit students about the government's educational and quota policy, its effectiveness, and implications in educational institutions?

- What are the various manifestations of (implicit as well as explicit) prejudice and discrimination against Dalit students?

\section{Methods}

This study adopted a qualitative approach, as it was principally concerned with capturing participants' direct experiences in their natural setting to produce a rich and thick description of the phenomena under study (Strauss \& Corbin, 1998; Patton, 2002). Interpretative Phenomenological Analysis (IPA) as a method of data analysis was used to get close to the participants' personal world, or in the words of Conrad (1987) "an insider's perspectives." IPA is focused on conducting a detailed examination of (a) participants' lived experiences, (b) what meanings participants derive from those experiences, and (c) how participants make sense of those experiences (Smith, 2011).

\section{Participant Selection and Interview}

The University of Himalaya is a public state university located in Uttar Pradesh. Caste is a sensitive issue and Dalits do not discuss such issues openly, fearing backlash. They avoid discussing reservation and caste-related issues even with their friends from UC. They only discuss such issues when they are with people of their own community or with someone trustworthy enough to share their innermost feelings. They also feel comfortable where they understand that the person talking to them would not meet them again; for example, when travelling by bus or train. However, they generally talk about caste when they are in a group; otherwise, they avoid such discussion, fearing verbal or physical violence.

As author of this study, I contacted students living in university hostels through a common friend living in one of those hostels. Initially when I told students about audio-recording the interview, they were skeptical about the confidentiality of their identity. However, after I explained to them the whole process and the use of a pseudonym in place of their real names and also for other identifying details, they agreed to the interview. My own low caste identity helped me in winning their trust for this study. 
In the beginning, a total of seven Dalit students (7 males) studying or having studied at the University of Himalaya were selected for this study through purposive sampling (Appendix A). The inclusion criteria used were: (a) the participant should be enrolled or have passed an undergraduate, graduate, or doctoral level course at the University of Himalaya and (b) the participants should belong to a Dalit community. Later, six more participants (4 males and 2 females) were selected through snowball sampling.

An informed consent form was signed by all the participants. Over the course of a week, in-depth interviews were conducted at the hostels or at the participants' homes. The minimum and maximum length of the interview was 35 minutes and 75 minutes respectively. The average interview length was 50 minutes. While most of the participants expressed their views in an open, direct, and detailed fashion, some participants found it difficult to go through the painful experiences of describing their exploitation, discrimination, exclusion, and humiliation at the hands of UC people. At times, their eyes became moist while narrating their own experiences at higher education institutions.

A semi-structured interview was conducted in the mother tongue of the participants, Hindi. The open-ended questions were focused on three areas of academic experience: fellow students, faculty, and administration (Appendix B). I converted the transcripts into English and used IPA to understand and interpret their perspectives.

\section{Data Analysis}

Data gathering and analysis are not separate activities in qualitative studies (Creswell, 2013). Data analysis starts from the very first step of data collection. Data analysis in IPA occurs in the following stages:

1. immersing oneself in the data through reading and re-reading of the transcripts;

2. conducting initial line by line coding;

3. conducting focused coding, which is an organic process of studying and assessing the initial codes to discern patterns/themes among the codes;

4. searching for a connection among emergent themes;

5. moving to the next case; and

6. looking for patterns across cases. (Smith, Flowers, \& Larkin, 2012)

I also maintained a journal that provided an interactive space to engage in reflexivity on data, codes, ideas, hunches, and researcher assumptions and biases.

Member check, also known as respondent validation, is a technique used in qualitative research to enhance the credibility of the findings. After collecting the 
data and initial analysis, I contacted the participants and shared the tentative interpretation/findings to ensure that the data were not misinterpreted.

\section{Researcher's Stance}

As a researcher, I am drawn to the constructionism worldview, which states that "all knowledge, and therefore all meaningful reality as such, is contingent upon human practices, being constructed in and out of interaction between human beings and their world, and developed and transmitted within an essentially social context" (Crotty, 2010, p. 42). According to this worldview, meaning is neither discovered nor created, but constructed through interaction with people and their surroundings. Therefore, my perspective as a researcher is one of the many perspectives about the studied phenomena.

My own social identity of an OBC, having been born and brought up in a lower middle-class family in a rural part of Utter Pradesh, offered me experiences of discrimination, exclusion, and humiliation during my own educational journey. As a school counselor, I witnessed instances where my clients, coming from Dalit and other marginalized communities, reported caste-based exclusion and humiliation. These experiences played a key role in generating my strong interest in advocacy and social justice. In this study, my own identity as a member of low caste was helpful as well as sometimes challenging. Having come from a similar social background helped me in understanding and interpreting their experiences; however, at times, it created biases as well. To minimize my own biases, I kept a separate journal to keep a tab on my feelings.

\section{Results}

After analyzing the interview transcripts of 13 participants through initial coding and transformation of initial coding into themes, I consolidated themes into six broad categories.

Table 1

Master Table of Themes

Sl. Themes

1: Dalit students' experiences with classmates

2: Dalit students' interaction with faculty

3: Dalit students' experiences with administration

4: Dalit students' perception of quota/reservation

5: Learned self-devaluation

6: Rental preferences of landlords and challenges for Dalitst 
The selection of themes is not purely based on their prevalence within the data. I considered other factors such as richness of detail in an account as well as how it highlights other aspects of the research question (Charmaz, 2004; Creswell, 2013; Smith \& Osborn, 2008).

\section{Dalit Students' Experiences with Classmates}

Participants reported that UC students generally do not mind socializing with Dalit students on campus. However, they rarely invite Dalit students to their homes for academic or non-academic purposes such as during festivals or marriage/social ceremonies. The reason is not that the UC students do not want to invite their Dalit friends to their homes; it is the fear of backlash from the family and community that hinders them from inviting their Dalit friends into their homes. Caste-based prejudices are very common among the older generation of UC as compared to the younger generation. UC students avoid confrontation with their families on these issues and so do not invite Dalit friends to their homes.

Participants shared that the older generation of UC is the main source of inculcation of caste-based values and prejudices among the younger generation of UC. Gurpreet, a Dalit student preparing for competitive examination, shared his experience.

A few months ago, there was election for the village chief in our district. A candidate from Dalit community was also contesting the election. One day I was sitting at a local shop. A seventy-year-old lady from an adjoining village came there, and she started talking to me. Assuming that I am from UC community, she told me, "Now-a-days, Chamars are also contesting elections. Do not vote for Chamar candidate. Chamars have been our slaves for hundreds of years. How a Chamar can be our village representative? Chamars are very low by birth." After she left, I thought, "This old lady must be teaching the same values to her children and family."

Most of the participants reported that UC students behave normally and have cordial relations with Dalit students in the beginning of the semester when caste identities are hidden. As time passes and caste identities are disclosed, UC students start ignoring Dalit students. However, this kind of behavior is observed in only a few UC students, not all. Priyadarshi shared his experience during his B.Ed. (Bachelor of Education) coursework, how his close friend from UC "felt embarrassed to find that he is a Chamar" later in the semester and distanced himself from Priyadarshi afterwards.

Disclosure of caste identities of Dalit students makes them vulnerable to various kinds of prejudice and discrimination, such as having a hostile attitude towards Dalit students, attributing Dalit students' academic achievements to quota, and using implicit humiliating comments based on negative caste stereotypes. Participants shared that they rarely face or feel caste prejudice and discrimination during elementary, middle, or high school from fellow UC students. Caste-based 
social identities of students take shape gradually as they move towards higher education when UC students start harboring a feeling of caste-based superiority over Dalit students. This feeling of superiority turns into feelings of disdain when UC students realize that the quota system is not for them but for Dalit. A Dalit student may get admission in a college with lower grades but UC students may not. In such scenarios, UC students start attributing their academic failures to the quota system. Shubham, who completed his M.Sc. (Master of Science) and B.Ed. from the University of Himalaya, shared his experiences with fellow classmates.

But after 12th grade, when [UC] children start becoming more socially conscious, they [upper caste] start harboring feelings of caste-based superiority. And after that they start ignoring Dalit students. The same student, who was my friend till 12th grade, starts ignoring me [because of my affiliation to low caste]. Further, this distance starts widening as they [UC] realize that they are not eligible for the benefits of quota/reservation system. They are jealous of us because of the quota [for Dalit]. They think we are responsible for their academic failures.

Dalits are stereotyped as submissive and docile and are not expected to be assertive. This social stereotype about Dalit is due to thousands of years of exploitation, exclusion, humiliation, and servitude at the hands of UC people. The level of tolerance for being open and assertive is different for students of different castes. The participants shared that tolerance for being assertive and vocal for UC students is much higher as compared to Dalit students. Being assertive and vocal in expressing one's opinions about social issues such as caste, religion, and reservation for a Dalit student may make him vulnerable to caste-based humiliation, exclusion, and discrimination. Subham, further, shared how he was humiliated by UC students because of his assertive nature and open challenge to the Hindu caste system in various debates during his B.Ed. coursework.

To be frank, I was targeted for speaking out against caste system. Everyone in the class used to say, "This boy is quarrelsome and speaks a lot against caste system." Whenever my turn came in any social/cultural programs, they used to announce, "Now, Shubham Kumar is coming." They emphasized a lot on "Kumar" insinuating my Dalit identity.

The data suggest that the socialization process at higher education institutions depends on three factors: caste affiliation, economic condition, and academic achievement. The interaction of these three factors, along with individual personality dispositions, determines a student's experience of socialization on campus. Dalit students generally belong to families with poor economic conditions that negatively influence their access to good study materials, extra coaching classes, and freedom from household responsibilities, which, in turn, hampers their academic achievements. Of the three factors, Dalit students generally do not have any factor in their favor and thus find it difficult to mingle with other castes students on campus. They are limited to their own group members. 


\section{$\left[\begin{array}{ccc}\text { Caste } \\ \text { Affiliation }\end{array} \times \begin{array}{c}\text { Economic } \\ \text { Condition }\end{array} \times \begin{array}{c}\text { Academic } \\ \text { Achievement }\end{array}\right]=\begin{gathered}\text { Socialization at } \\ \text { Campus }\end{gathered}$}

Figure1. Factors determining socialization process at higher education institutions

Harish, a research scholar in economics, shared his experiences of interaction of caste affiliation and economic condition in the socialization process on campus.

If the economic condition of your family is good, then caste identities do not matter much because you will be able to spend money in your group. Most of the students of Dalit community belong to a very poor family background. Therefore, they are unable to mingle in a group of UC students who generally belong to families having good economic resources. Most [Dalit] students spend time with students of their own caste.

In college campuses, there is a common tradition of showing respect towards senior students by juniors. Juniors pay respect by touching feet, using common greeting practices such as "Good Morning," "Namaste," or "Hello Sir." Touching feet is a traditional Indian custom to show love and respect towards elderly people like grandparents, parents, teachers, and relatives (Giri, 2006). In educational settings, touching the feet of one's teachers is not mandatory; however, it is a social expectation associated with being a good student (Giri, 2006). Dalit senior students feel that UC juniors ignore senior Dalit students because of their caste affiliation. UC juniors show respect only when they need some help from Dalit seniors. Harish, a senior research scholar, shared:

They [UC] also practice discrimination in another form. Junior students from UC category express greetings according to one's caste. So even if you [a Dalit] are a senior research scholar, they do not say "Namaste" to you.

When it comes to showing respect towards faculty members by students, the participants reported that UC students avoid touching feet of Dalit faculty members. UC students have feelings such as, "How can a Brahmin touch the feet of a Chamar?" Even if they do so, it is just a formality rather than a genuine feeling of respect. Generally, UC students offer greetings (Good Morning, Hello Sir, etc.) from a distance. Brahman, a Dalit student who completed his degree in law from University of Himalaya, shared:

Many students in our group used to say, "How can you touch his [Dalit faculty] feet, he is from SC." There was a teacher whose caste they [upper caste students] could not decipher, they used to call him Chamar; so if a student touched his feet, they used to tease him saying, "He touches the feet of a Chamar." 


\section{Dalit Students' Interaction with Faculty}

Almost all participants reported that they experienced caste prejudice and discrimination from a few UC faculty members. These caste-based prejudices and discrimination increase as Dalit students move towards master's and $\mathrm{PhD}$ programs. Discrimination by faculty is manifested in various forms, such as paying less or no attention to Dalit students in class, assigning lower marks/grades to Dalit students in practical examinations, and creating hurdles in $\mathrm{PhD}$ registration and completion. Abhimanyu shared how, during his Master's in Economics, a UC faculty ignored Dalit students when they sought help in understanding any concept related to their coursework.

There was a Shuklaji [UC]. Whenever we [Dalit] students go to ask anything related to studies, he used to ignore us by saying "come later" or "I am busy now." However, when other students [UC] asked anything, he used to offer them seats, helped them, and cooperated with them like his family members. It is because of the caste feelings.

Humiliation at the hand of UC teachers is also a fairly common event in higher education. It takes place in various forms such as asking one's surname and caste affiliation publicly in the classroom, talking in a rude manner, and passing such humiliating comments as "taking admission for collecting scholarships," or "you SCs will remain SCs." However, all the participants emphasized that such behaviors are practiced by only a few UC teachers.

Another mechanism that UC teachers sometimes use to discriminate against Dalit students is encouraging UC students to make their own group and exclude Dalit students. Rajesh shared his experience during his Diploma in Mechanical Engineering.

There was a UC boy who had a good friendship with an SC boy. A teacher pressurized the UC boy to break the friendship saying, "Why you live with Chamars?"

Having a role model from one's own social group is the key to self-esteem and evaluation of the group by its members. Role models are important to neutralize stereotype threat experienced by minorities or suppressed classes in any society (Aronson, Fried, \& Good, 2002). Inclusion of Dalit icons in textbooks as well as in the cultural fabric of higher education is important for making Dalit students feel more comfortable and confident about their educational journey. However, teachers in higher education rarely discuss Dalit icons such as Dr. Bhim Rao Ambedkar, Jyotiba Phule, and Sant Ravidas. Kusumlata, a second-year B.A. (Bachelor of Arts) student in one of the affiliated colleges of University of Himalaya, shared her experience with exclusion of Dalit icons in cultural programs at the college.

There was NSS (National Social Service) camp in our college. We were divided in many groups and each group was given a particular name based 
on some great historical personalities. So, I named my group as Dr. Bhim Rao Ambedkar [A great Indian economist, philosopher, nationalist, and messiah of Dalit people]. Some teachers and the manager of the college objected, "You did not get any other great historical Indian personality [that you had to name it Ambedkar]?" I protested, "What is wrong with Dr. Ambedkar? Is he not a great Indian?" I had an argument with him and he could not defy my arguments.

Research requires a high level of cooperation and coordination between a research scholar and his or her supervisor. Dalit research scholars at the University of Himalaya reported a high level of discrimination from their UC supervisors. The first hurdle that a Dalit scholar faces in research is $\mathrm{PhD}$ registration. Despite fulfilling all eligibility criteria of $\mathrm{PhD}$ registration, Dalit students are often told that no seats are vacant. Abhimanyu, who achieved more than $60 \%$ marks in his Master's and qualified UGC NET examination, shared his own experience. (UGC NET is an eligibility examination for enrollment in doctoral programs and teaching positions in colleges and universities.)

I have also qualified UGC NET, but I am still without [PhD] registration. There is a faculty in Department of Education, Ragini (pseudonym) ma'am. She is saying that seats are vacant; she is a Dalit and she has asked me to meet the Head of Department and get permission to enroll under her. But the Head of Department is a Brahmin [UC]. He says that no seats are vacant.

Even after such initial hassles of registration if one gets registered, Dalit research scholars reported that UC supervisors do not cooperate and delay their $\mathrm{PhD}$ submission as long as possible. Supervisors neither give attention nor respect to Dalit scholars. When approached for guidance on how to proceed and plan $\mathrm{PhD}$ research work, UC supervisors simply tell Dalit students to "ask other fellow students." When Dalit students show some work, UC supervisors avoid giving constructive feedback and simply say, "This is not fine, go and rewrite it." Lack of cooperation from supervisors is the key challenge that Dalit students reported in the present study.

\section{Dalit Students' Experiences with Administration}

Students' interaction with college administration is part of their educational experiences. Works related to documentation of educational data, submission of fees, and matters related to scholarships are the common occasions when students interact with administration of the college. Participants reported castebased prejudices and discrimination when Dalit students approached college administration for any related work. One of the key reasons behind this is the lack of representation of Dalits in college administration. Praveen, a research scholar at the University of Himalaya, shared his experiences with administration.

They do their [UC students'] work first, then Dalit student's. They respond 
politely and directly to UC students, and OBCs are treated a little impolitely and indirectly. But with Dalit students, they behave very rudely and offer vague answers such as "Come tomorrow, we don't know, it is not related to us, go there etc." Ultimately, they do the work but after a lot of delay and harassment.

Harish, another research scholar at the University of Himalaya, feels that domination of UC employees in college administration is responsible for prejudice against Dalit students.

Yes, discrimination is also there because the same $90 \%$ ratio is also there in administration as well. Most of the employees are from UC category. They taunt Dalit students, "You take admission only to collect scholarship, you come here for that only, etc."

Mridula, another female research scholar who is getting funding through the Rajeev Gandhi Fellowship, shared her experience. The Rajeev Gandhi National Fellowship scheme is for Dalit students who want to pursue higher studies.

Whenever I go to collect my scholarship, they make me feel like they are paying from their own pockets.

\section{Dalit Students' Perception of Quota}

All the participants feel that the reservation policy has played a key role in their educational journey in the form of financial support and admission in higher education institutions. All three research scholars who took part in this study have received financial support in the form of a Rajeev Gandhi National Fellowship. Some got full tuition fee reimbursement during their B.Ed. coursework. Others have received financial support during both undergraduate and graduate years. Most of the students who participated in this study are living in hostels made for only SC/ST students and available totally free of cost. However, some students feel that the current government in the state of Uttar Pradesh is anti-Dalit, as it has decreased the financial support offered to Dalit students as well as abolished the reservation system in government job promotions.

Another recurring theme that emerged concerning quota/reservation policy is the lack of proper implementation of the quota policy after national independence in 1947. One example of this ineffective implementation of the quota policy is the low representation of SC/ST and OBC teachers in higher education. Fifty-eight percent of faculty positions for SC/STs and OBCs are still vacant in central universities (Mohanty, 2016). There is no denying that representation of SC/STs has improved significantly; however, it is still significantly behind its goals. The participants shared that the obstructionist attitude of UC faculty and administration in implementing quotas in colleges and universities is one of the reasons for low representation of Dalit faculty in higher education. Participants also shared that lack of proper representation of Dalit faculty is one of the reasons behind 
continuing prejudice and discrimination against Dalit students. As Harish explained:

Reservation policy has not been implemented properly yet. First, they [UC] tried to postpone it by saying "No student found," then they started saying "No suitable candidate found." So, they keep on obstructing implementation of reservation. There were some reports where it was found that they filled those SC/ST seats by UC candidates where SC/ST candidates were not available.

\section{Learned Self-Devaluation}

Learned self-devaluation is a tendency among people to devalue themselves as an individual or as a group and accept imposed inequalities/injustices as legitimate, fate-based, or God-made. This tendency is commonly observed among people from Dalit communities who have been suppressed and exploited for thousands of years through the Indian caste system. This tendency is not inherent by birth, but it starts from social devaluation of a group or community by other dominant groups. Parental inculcation of such values perpetuates this behavior among Dalit students, who commonly exhibit selfdevaluation behavior on colleges and university campuses. Kusum Lata, a secondyear B.A. student, shared her experiences of Dalit students' learned selfdevaluation behavior.

Dalits, I don't know why, behave in a fearful manner. They themselves think that they are low and downtrodden people. They should not think like that; even if we have little [financial resources], we should live with dignity and pride. I think that our community has some problems [of self-denigrating nature, poor self-image and low self -confidence].

This tendency of self-devaluation affects all aspects of their personality and group behaviors. The submissive and fearful nature of Dalit students, avoidance of classroom interaction and lack of assertiveness, and feeling of helplessness in the face of prejudiced and discriminatory behaviors of UC are some of the common symptoms of this tendency. Positive changes have occurred in the last few decades, and political and educational awareness has increased significantly among Dalits; however, these developments are limited to a tiny fraction of the Dalit population (Sukumar, 2013).

\section{Rental Preferences of Landlords and Challenges for Dalit Students}

Generally, colleges and universities do not have enough hostels to accommodate all enrolled students. Therefore, students have to find private accommodation. Finding a place to stay is another challenge that Dalit students face because of social exclusion practiced by landlords in rental preferences. A 
study led by Thorat et al. (2015) found that even in cosmopolitan cities like New Delhi, which is considered one of most migrant-friendly cities in India, social exclusion is practiced by landlords in rental preferences. The researchers concluded that non-monetary motives often prevail among landlords renting out houses. When the researchers posed as potential renters and contacted landlords by telephone, $18 \%$ of Dalit and $31 \%$ of Muslims were rejected while rejection of UC Hindu tenants was $0 \%$. The situation became worse when face-to-face contact was made; $44 \%$ Dalit and $61 \%$ Muslims were rejected while rejection of UC Hindus was only $3 \%$ (Thorat et al., 2015). This discrimination also means that Dalits and Muslims have to pay more than others to find a place to stay. Participants reported that finding a private accommodation is tough as they either have to hide their caste identity or pay extra money to housing-brokers to find a place.

\section{Discussion}

Most of the Dalit students in higher education are the first generation of learners and come from educationally and financially deprived families. As they hardly receive any guidance from their own families and communities, they are mostly dependent on faculty and university administration for educational support and guidance. Also, because of their poor financial background, they find it hard to pay for private tuition or coaching classes and other educational resources that are easily available for students from strong financial backgrounds. Thus, Dalit students are more dependent on their faculty for educational guidance and support than their peers. However, behavior of at least a few UC faculty and administration with Dalit students at the University of Himalaya can be characterized as apathetic, unsupportive, and discriminatory in some cases.

Prejudice and discrimination against Dalit students can further be understood from SIT and related concepts from social sciences. According to SIT, those who view the social world hierarchically are more prone to have prejudiced attitudes towards low status groups. This has been found especially true of those who believe in the superiority of their own group (Sidanius \& Pratto, 2001). The Indian caste system divides Indian society into four mutually exclusive hierarchical categories based on the notion of purity and pollution. The hierarchy of these categories from the top is Brahmin (priests and teachers), Kshatriya (warriors), Vaishya (Traders) and Shudra (workers and labourers) (Maurya, 2016). Beyond the four categories are untouchables (achhoot). Dalit as a group include untouchables and most of the shudras. Brahmins and Kshatriya at the top of the caste hierarchy assume superiority of their caste and therefore are more prone to harbour prejudice against Dalits. As the representation of Dalits at the faculty and administration level is still very low in higher education, Dalit students are more prone to caste-based prejudice and discrimination (Mohanty, 2016).

Rigid categorical thinking that refers to an innate human tendency to assign people or things to categories and then use those categories as if they represent something in the real world is another key ingredient of prejudice (Plous, 2003). 
Caste in India is a social categorization conceptualized more than 2000 years ago that gradually turned into a rigid social segregation characterized by endogamy and permanent affiliation to a particular caste decided by birth (Jaiswal, 2014). Rigid categorical thinking of the UC individuals seems another factor responsible for prejudice against Dalit.

Prejudice and discrimination against Dalit students in higher education can also be understood from another social phenomenon-in-group bias. In-group bias refers to a social phenomenon in which people tend to favor their own group members (Aberson, Healy, \& Romero, 2000). Numerous studies in social psychology have found that people who are high in self-esteem, and who therefore have the most to lose if their self-esteem is undercut, exhibit more in-group bias than do people having low self-esteem (Aberson, Healy, \& Romero, 2000). This explains why people from UC are more vulnerable to in-group bias than Dalit because of high self-esteem associated with being born into a UC family.

Also, people are more likely to show prejudice when they experience a drop in their self-esteem (Plous, 2003). Government's social welfare programs and affirmative action policies such as reservation in government jobs and higher education have helped Dalits make significant progress after independence (Thorat, Tagade, \& Naik, 2016). The progress made by Dalit and other backward castes does not always go well with the high self-esteem of people of UC. This may be another reason for prejudice and discrimination practiced by upper caste people.

Another important factor associated with prejudice is how in-group and outgroup members interpret each other's behavior. In social psychology, this phenomenon is known as Causal Attributions (Aronson \& Wilson, 2015). It functions both as a symptom and a source of prejudice (Plous, 2003). For example, when a UC student performs well in academics, upper caste students and teachers commonly attribute it to talent, hard work, and perseverance; however, a success story of a Dalit in academia is commonly attributed to quota/reservation. As a result, upper caste faculty and students, having such causal attributions towards Dalit students, are more likely to harbor prejudice towards Dalit students at campuses. Dalit students are also likely to attribute the success of UC students to strong financial backgrounds that enable them to access all resources including proper food, accommodation, freedom from day-to-day family hiccups, access to good study materials, extra private tuition classes, and support from faculty, administration, and students.

\section{Conclusion}

Caste prejudice and discrimination against Dalit students at the University of Himalaya and its affiliated colleges is a reality, albeit a subtle one. Examples include humiliating Dalit students by asking their surnames to decode their caste affiliation, ignoring Dalit students in offering academic support by faculty, 
stereotyping Dalit students as lazy and studying only for scholarships by faculty and administration, showing differential treatment towards senior Dalit scholars by UC junior scholars in terms of offering respect, and avoiding Dalit students for making friendship. Socialization on campus is another area of concern. Dalit students' affiliation to "low caste" and their weak financial condition hamper their campus socialization. Dalit students perceive that the Hindu caste system, which put them at the bottom of the social hierarchy, is still widely practiced, and quota for them is the key reason behind prejudiced attitude and discrimination against them in higher education. Learned self-devaluation among Dalit students is another phenomenon that hampers their self-concept and hence their overall experience of higher education.

These findings cannot necessarily be extrapolated to other well-known institutions, and further research is required covering a large number of higher education institutions. Also, including both Dalit and non-Dalit participants from diverse backgrounds would have further enriched the data and may have offered some new perspectives regarding the experiences of Dalit students. Nevertheless, the present study has implications for both government and non-government organizations responsible for creating and implementing effective policies to promote higher education among Dalits. I recommend that appropriate measures be taken by the college/university to sensitize faculty and administration to the challenges faced by Dalit students. In addition, remedial classes and a separate committee headed a Dalit faculty to address complaints of Dalit students should also be established. The university should also ensure representation of Dalit students on all student committees to promote more interpersonal exchange among Dalit and UC students.

\section{References}

Aberson, C. L., Healy, M., \& Romero, V. (2000). Ingroup bias and self-esteem: A meta-analysis. Personality and Social Psychology Review, 4(2), 157-173. doi:10.1207/S15327957PSPR0402_04

Abrams, D., \& Hogg, M. (2016). Social identifications: A social psychology of intergroup relations and group processes. New York, NY: Taylor \& Francis.

Aronson, E., \& Wilson, T. (2015). Social psychology. New York, NY: Pearson.

Aronson, J., Fried, C., \& Good, C. (2002). Reducing the effects of stereotype threat on African american college students by shaping theories of intelligence. Journal of Experimental Social Psychology, 38(2), 113-125. doi:10.1006/jestp.2001.1491

Biswas, S. (2016, Jan. 20). Why are India's Dalit students taking their lives? Retrieved from http://www.bbc.com/news/world-asia-india-35349979

Charmaz, K. (2004). Premises, principles, and practices in qualitative research: 
Revisiting the foundations. Qualitative Health Research, 14(7), 976-993. http://dx.doi.org/10.1177/1049732304266795

Conrad, P. (1987). The experience of illness: Recent and new directions. Research in the Sociology of Health Care, 6, 1-31.

Couderé, H. (2016, May 19). India: Violence against Dalits on the rise. Retrieved from https://thediplomat.com/2016/05/india-violence-against-dalits-on-therise/

Creswell, J. W. (2013). Qualitative inquiry \& research design: Choosing among five approaches. Thousand Oaks, CA: Sage.

Crotty, M. (2010). The foundations of social research. Thousand Oaks, CA: Sage.

Deshpande, S., \& Zacharias, U. (2013). Beyond inclusion: the practice of equal access in Indian higher education. New Delhi, India: Routledge.

Dhar, A. (2016, September 28). AlIMS rejects Thorat report. Retrieved from http://www.thehindu.com/todays-paper/tp-national/tp-newdelhi/AllMSrejects-Thorat-report/article14838292.ece

Feinberg, W. (2005). Affirmative action. In Hugh LaFollette (Ed.), The Oxford handbook of practical ethics (pp.1-31). Oxford, United Kingdom: Oxford University Press. doi:10.1093/oxfordhb/9780199284238.003.0012

Giri, V. N. (2006). Culture and communication style. Review of Communication, 6(1-2), 124-130. doi:10.1080/15358590600763391

Jaiswal, T. (2014). Indian arranged marriages: A social psychological perspective. New Delhi, India: Routledge.

Karthikeyan, D. (2011, Sept.5). Suicide by Dalit students in 4 years. The Hindu, Retrieved from http://www.thehindu.com/todays-paper/tp-national/tptamilnadu/suicide-by-dalit-students-in-4-years/article2425522.ece

Kumar, A. (2012, March 14). The death of Anil Meena. The Indian Express. Retrieved from http://indianexpress.com/article/opinion/columns/the-deathof-anil-meena/

Maheshwari, S. R. (1997). Reservation policy in India: Theory and practice. Indian Journal of Public Administration, 43(3), 662-679.

Maurya, R. K. (2016). Do Hindi cinema \& television serials propagate caste stereotypes through surnames of characters: A content analysis. The International Journal of Indian Psychology, 3(3), 157-181. doi: $18.01 .055 / 20160303$

Mohanty, B. (2016, Feb.1).Caste ceiling on campuses. The Telegraph, Retrieved from http://www.telegraphindia.com/1160201/jsp/frontpage/story_66893. jsp\#.VuZXpfl97IV

Ovichegan, S. (2013). The experiences of Dalit students and faculty in one elite university in India: An exploratory study (Doctoral dissertation). Retrieved from https://kclpure.kcl.ac.uk/portal/files/13413516/Studentthesis- 
Samson_Ovichegan_2013.pdf

Pathak, V., \& Sampath, G. (2016, October 18). U.P., Bihar lead in crimes against Dalits. Retrieved from http://www.thehindu.com/data/U.P.-Bihar-lead-incrimes-against-Dalits/article14506278.ece

Patton, M. Q. (2002). Qualitative research and evaluation methods. Thousand Oaks, CA: Sage.

Plous, S. (2003). The psychology of prejudice, stereotyping, and discrimination: An overview. New York, NY: McGraw-Hill.

Sidanius, J., \& Pratto, F. (2001). Social dominance: An intergroup theory of social hierarchy and oppression. Cambridge, England: Cambridge University Press.

Rehman, S. (2017, January 20). Rohith is the 23rd Dalit student suicide in institutes like AIIMS and IITs. Catch News. Retrieved from http://www.catchnews.com/national-news/blood-on-books-rohith-vemulas-is-the-23rd-dalit-student-suicide-in-under-a-decade-bandaru-dattatreyaabvp-bjp-rahul-gandhi-thorat-committee-caste-1453210563.html

Singh, R. (2016, January 23). HRD ministry fails to implement Thorat committee recommendations. Retrieved from https://www.dnaindia.com/india/reporthrd-ministry-fails-to-implement-thorat-committee-recommendations2169141

Singh, A. K. (2013). Defying the odds: The triumphs and tragedies of Dalit and Adivasi students in higher education. In S. Deshpande \& U. Zacharias, Beyond inclusion: The practice of equal access in Indian higher education (pp. 205-221). New Delhi, India: Routledge.

Smith, J., \& Osborn, M. (2008). Interpretative phenomenological analysis. In Smith, J. (Ed.), Qualitative psychology: A practical guide to research methods (pp. 53-81). London, England: Sage.

Smith, J. A. (2011). Evaluating the contribution of interpretative phenomenological analysis. Health Psychology Review, 5(1), 9-27. doi:10.1080/17437199.2010.510659

Smith, J. A., Flowers, P., \& Larkin, M. (2012). Interpretative phenomenological analysis: Theory, method, and research. Thousands Oaks, CA: Sage.

Strauss, J., \& Corbin, J. (1998). Basics of qualitative research: Techniques and procedures for developing grounded theory. Thousand Oaks, CA: Sage.

Sukumar, N. (2013). Quota's children: The perils of getting educated. In S. Deshpande \& U. Zacharias, Beyond inclusion: The practice of equal access in Indian higher education (pp. 205-221). New Delhi, India: Routledge.

Tripathy, J., Thakur, J., Jeet, G., Chawla, S., Jain, S., \& Prasad, R. (2016). Urban rural differences in diet, physical activity and obesity in India: Are we witnessing the great Indian equalization? Results from a cross-sectional 
STEPS survey. Bmc Public Health, 16(1), 1-10. doi:10.1186/s12889-0163489-8

Thorat, S., Banerjee, A., Mishra, V. K., \& Rizvi, F. (2015). Urban rental housing market: Caste and religion matters in access. Economic and Political Weekly, 50(26-27), 47-53.

Thorat, S. (2016, January 26). Discrimination on the campus. The Hindu. Retrieved from http://www.thehindu.com/opinion/lead/Discrimination-on-the-campus/ article 14019816.ece

Thorat, S., Tagade, N., \& Naik, A. K. (2016). Prejudice against reservation policies: How and why? Economic and Political Weekly, 51(8), 61-69.

Thorat, S., Shyamprasad, K. M., \& Srivastava, R. K. (2007). Report of the committee to enquire into the allegation of differential treatment of SC/ST students in All India Institute of Medical Science, Delhi. Thorat Committee, 2-77. Retrieved from http://www.nlhmb.in/Reports\%20AllMS.pdf

Thornton, M., Bricheno, P., Iyer, P., Reid, I., Wankhede, G., \& Green, R. (2010). Diversity and social integration on higher education campuses in India and the UK: Student and staff perspectives. Research in Post-Compulsory Education, 15(2), 159-176. doi:10.1080/13596741003790682

Turner, J. C., Reynolds, K. H. (2001). The social identity perspective in intergroup relations: Theories, themes, and controversies. In R. Brown \& S. Gaertner (Eds.), Blackwell handbook of social psychology: Intergroup processes (pp. 133-152). doi:10.1002/9780470693421.ch7 
Appendix A:

Participant Details

\begin{tabular}{|c|c|c|c|c|}
\hline $\begin{array}{l}\text { SI } \\
\text { No. }\end{array}$ & $\begin{array}{c}\text { Name of } \\
\text { Participant } \\
\text { (pseudonym) }\end{array}$ & Gender & $\begin{array}{c}\text { Name of } \\
\text { Department }\end{array}$ & $\begin{array}{l}\text { Educational } \\
\text { Qualifications }\end{array}$ \\
\hline 1 & $\begin{array}{l}\text { Abhumanyu } \\
\text { Kumar }\end{array}$ & Male & Education & M.Ed. NET(Education) \\
\hline 2 & Jaswant & Male & Education & B.Sc. , B.Ed. \\
\hline 3 & Brahman & Male & Law & B.A., L.L.B. \\
\hline 4 & Kusumlata & Female & Drawing & B.A. \\
\hline 5 & Priyadarshi & Male & Education & B.Sc. , B.Ed. \\
\hline 6 & Praveen & Male & Economics & M.A. PhD(Pursuing) \\
\hline 7 & Prem & Male & History & M.A. B.Ed. \\
\hline 8 & Rajesh & Male & Polytechnic & $\begin{array}{c}\text { Diploma in Mechanical } \\
\text { Engineering }\end{array}$ \\
\hline 9 & Gurpreet & Male & Education & B.Sc. , B.Ed. \\
\hline 10 & Harish & Male & Economics & M.A. PhD(Pursuing) \\
\hline 11 & Shubham & Male & M.Sc. & M.Sc., B.Ed. \\
\hline 12 & Devashish & Male & Economics & M.A. PhD(Pursuing) \\
\hline 13 & Kanika & Female & Geography & M.A. PhD(Pursuing) \\
\hline
\end{tabular}

\section{Appendix B: \\ Semi-structured Interview Questions}

(Note: Lead question in bold, probing questions un-bold)

Q. 1- Could you tell me about your personal background? (Family members, early education etc.)

Q. 2- When and how did you get admission here? (What were the motivations behind going for higher education? Is there any event during your formative years which motivated you for higher education?)

Q. 3- Could you share your experiences with the faculty members? ( Their attitude towards you and other Dalit students; treatment in class; support in academic work; appreciation and moral support; marks and grades; attitude of teachers towards reservation system.)

Q. 4- Could you share your experiences with the administration? (Their attitude towards Dalit and non-Dalit students) 
Q. 5- Could you share your experiences with the fellow students in class? ( Their attitude towards Dalit and non-Dalit students; treatment in class; support in academic work; appreciation and moral support; attitude of non- Dalit students towards reservation system; Do you think caste play a role in socialization at college/university such as making friends, having party etc.)

Q. 6- Describe your social life on campus. (Hostel life, friendship with Dalit and non-Dalit students)

Q.7- How you cope up with situations when you feel being discriminated by faculty, administration and fellow students? (Whom do you share such experiences? how do you respond when such things happen? etc.)

Q. 8- What are the redress mechanism in the college/university for the matters related to caste based discrimination, humiliation and exclusion? (Level of awareness about SC/ST cell and other bodies at district, state and national level etc.)

Q. 9- In your educational journey till now, what role quota/reservation has played? (Scholarship, admission or any other type of support)

Q. 10- What is your opinion about the reservation system? Do you think it's working well or some changes are required?

Q. 11- Could you tell me about differences within Dalit castes students? (Internal relations between various Dalit sub-castes or Dalits coming from various economic backgrounds)

Q. 12- Anything you want to discuss which you think I did not cover in this interview?

\section{Author Contact}

Rakesh Kumar Maurya, rmaurya@uwyo.edu, School of Counseling, Leadership, Advocacy, \& Design, University of Wyoming, 1000 E. University Ave. Laramie, WY 82071 U. S. A. 